\title{
CPD By the Minute: an innovative mobile application for continuing professional development in medicine
}

\author{
Alexandra Rotstein, MD - Rebecca Charow, MSc - Tina Papadakos, MA (Ed) • David Wiljer, PhD • \\ Peter Slinger, MD
}

Received: 5 May 2020/Revised: 29 July 2020/Accepted: 29 July 2020/Published online: 10 August 2020

(c) Canadian Anesthesiologists' Society 2020

\section{To the Editor,}

$C P D$ By the Minute is a web- and mobile-based multiple-choice question (MCQ) application ("app") that we have developed for continuing professional development (CPD). It relies on the concept of frequent, low-stakes testing to facilitate learning. ${ }^{1}$ Links to two MCQs are sent weekly to participating physicians to test their knowledge of clinical problem solving, practice standards, and guidelines in their fields. Participants must select a response to each question within one minute or the answer is considered incorrect. A detailed explanation and references follow immediately to help identify learning gaps. Performance feedback allows learners to compare their performance to their peer group.

A prototype app was created using Moodle, an open source learning platform (Moodle.org) with an inbuilt option to publish content in an app. The app feature was enabled and customized by the Cancer Education program at Princess Margaret Cancer Centre, University Health Network (UHN), Toronto. A single-group, mixed-methods design was used to evaluate the app for utility, user experience, perceived effectiveness, and educational

Electronic supplementary material The online version of this article (https://doi.org/10.1007/s12630-020-01788-0) contains supplementary material, which is available to authorized users.

A. Rotstein, MD

Deaprtment of Anesthesiology and Pain Medicine, University of Toronto, Toronto, ON, Canada

R. Charow, MSc $\cdot$ P. Slinger, MD ( $ه)$

University of Toronto, Toronto, ON, Canada

e-mail: Peter.Slinger@uhn.ca

T. Papadakos, MA (Ed) - D. Wiljer, PhD

University Health Network, Toronto, ON, Canada impact. $^{2}$ Ethical approval for this feasibility study was from the UHN Institutional Review Board. Eighteen volunteers from the University of Toronto Department of Anesthesia participated in the study: six staff anesthesiologists, four fellows, and eight residents. Participants used the app for a five-week trial period, completed a post-trial survey, and participated in a followup semi-structured interview. One of the MCQs, its corresponding answer, and critique are shown in the Electronic Supplementary Material as eFigs 1 and 2.

The app was well received among users (Table). Eightyeight percent $(16 / 18)$ of survey respondents said they would be likely or very likely to continue using the app beyond the study period and that they would pay for access. Sixty-four percent (11/17) of users gave the app a System Usability Scale score of $\geq 80$. $^{3}$

The app format has several unique strengths as a tool for CPD. It has the potential to reach a large number of physicians training in a variety of practice locations; it requires a low level of ongoing time commitment, facilitating longitudinal engagement; it identifies specific areas of weakness and strength, allowing physicians to better tailor their other CPD activities; and it provides a novel means of disseminating new practice information by incorporating essential updates into the weekly questions. The updated version of the app will use an algorithm to periodically re-cycle some questions to participants based on their previous incorrect answers. Educational research has shown that the intentional recall prompted by testing and spaced repetition of learning over time ${ }^{4}$ are effective strategies for long-term retention of knowledge. We will use the feedback from this feasibility study to refine the next version of the app. Access to a mobile app for CPD has the potential to improve the way that Canadian physicians engage in lifelong learning and could easily 
Table Post-study survey responses (Likert scale) by users of the CPD By the Minute app

\begin{tabular}{|c|c|c|c|c|c|}
\hline & $\begin{array}{l}\text { Very } \\
\text { likely/effective }\end{array}$ & Likely/effective & Somewhat & Not very & Not at all \\
\hline How likely are you to continue using the app? $(n=18)$ & $50.0 \%(9)$ & $38.9 \%(7)$ & $0.0 \%(0)$ & $5.6 \%(1)$ & $5.6 \%(1)$ \\
\hline How effective is the app as a learning tool for your practice? $(n=18)$ & $55.6 \%(10)$ & $22.2 \%(4)$ & $16.7 \%(3)$ & $5.6 \%(1)$ & $0.0 \%(0)$ \\
\hline How likely are you to recommend the app to your colleagues? $(n=18)$ & $50.0 \%(9)$ & $27.8 \%(5)$ & $11.1 \%(2)$ & $\begin{array}{l}11.1 \% \\
(2)\end{array}$ & $0.0 \%(0)$ \\
\hline $\begin{array}{l}\text { How likely are you to recommend the app to residents or fellows? } \\
\quad(n=18)\end{array}$ & $66.7 \%(12)$ & $27.8 \%(5)$ & $0.0 \%(0)$ & $5.6 \%(1)$ & $0.0 \%(0)$ \\
\hline
\end{tabular}

Data are represented as the percentage and individuals answering each question $(n)$

be integrated into the existing CPD framework used by the Royal College of Physicians and Surgeons of Canada. ${ }^{5}$

Disclosures None.

Funding University of Toronto.

Editorial responsibility This submission was handled by Dr. Hilary P. Grocott, Editor-in-Chief, Canadian Journal of Anesthesia.

\section{References}

1. Feldman M, Fernando $O$, Wan M, Martimianakis MA, Kulasegaram $K$. Testing test-enhanced continuing medical education: a randomized controlled trial. Acad Med 2018; 93: S30-6.
2. Arain M, Campbell MF, Cooper CL, Lancaster GA. What is a pilot or feasibility study? A review of current practice and editorial policy. BMC Med Res Methodol 2010; DOI: https://doi.org/10. 1186/1471-2288-10-67.

3. Brooke J. SUS: A ‘quick and dirty’ usability scale. In: Jordan PW, Thomas B, Weerdmeester BA, McClelland AL, editors. Usability Evaluation in Industry. London: Taylor and Francis; 1996. p. 18994.

4. Roediger HL, Karpicke JD. Reflections on the resurgence of interest in the testing effect. Perspect Psychol Sci 2018; 13: 23641.

5. Royal College of Physicians and Surgeons of Canada. The Maintenance of Certification Program (MOC) - 2020. Available from URL: http://www.royalcollege.ca/rcsite/cpd/maintenance-ofcertification-program-e (accessed August 2020).

Publisher's Note Springer Nature remains neutral with regard to jurisdictional claims in published maps and institutional affiliations. 